\title{
Nodular Mucinosis of the Breast in a Male: Reassessment of Diagnostic Criteria and Proposal for Its Classification as a Soft Tissue Tumor in the Myofibroblastoma and Spindle Cell Lipoma Spectrum
}

\author{
Maria Teresa Fernández-Figueras ${ }^{a} \quad$ Dmitry V. Kazakov ${ }^{c}$ \\ Raquel López Martos ${ }^{a}$ Isabel Ojanguren ${ }^{a} \quad J^{\prime}$ ordi Vila ${ }^{b}$ Aurelio Ariza ${ }^{a}$ \\ Departments of a Anatomic Pathology and b Plastic Surgery, Hospital Universitari Germans \\ Trias i Pujol, Universitat Autònoma de Barcelona, Badalona, Spain; ' Sikl Department of \\ Pathology, Charles University Medical Faculty Hospital, Pilsen, Czech Republic
}

\section{Key Words}

Breast $\cdot$ Nipple $\cdot$ Mucinosis $\cdot$ Myofibroblastoma

\begin{abstract}
Nodular mucinosis of the breast (NMB) is a rare entity with only a few cases described in the literature, most of them in young girls. All cases are located in the nipple and areolar area and microscopically consist of a multinodular myxoid mesenchymal proliferation. Bands of sclerotic collagen containing preexisting breast ducts and abundant vascularization are other features typical of NMB. No relation to Carney complex has been reported, and an indolent behavior is the rule in all patients. We present a case of NMB occurring in the nipple of a 46-year-old man and analyze the clinicopathological features of the other cases of NMB reported in the English literature, concluding that two of them most likely correspond to trauma-induced cutaneous focal mucinosis of the mammary areola. Finally, we review diagnostic criteria for NMB and elaborate an ontogenetic hypothesis based on both its morphological resemblance to myofibroblastoma and its immunohistochemical profile.
\end{abstract}

(c) 2014 S. Karger AG, Base

\section{Introduction}

Nodular mucinosis of the breast (NMB) is an exceedingly rare entity that was first described by Michal et al. [1] in 1998. All the reported cases involve the nipple and areolar regions of young or middle-aged individuals, usually women, and are characterized by an 
Fig. 1. a Marked nipple enlargement with multiple bluish areas and myxoid appearance. b Alcian blue stain highlighting the myxoid nature of the proliferation.
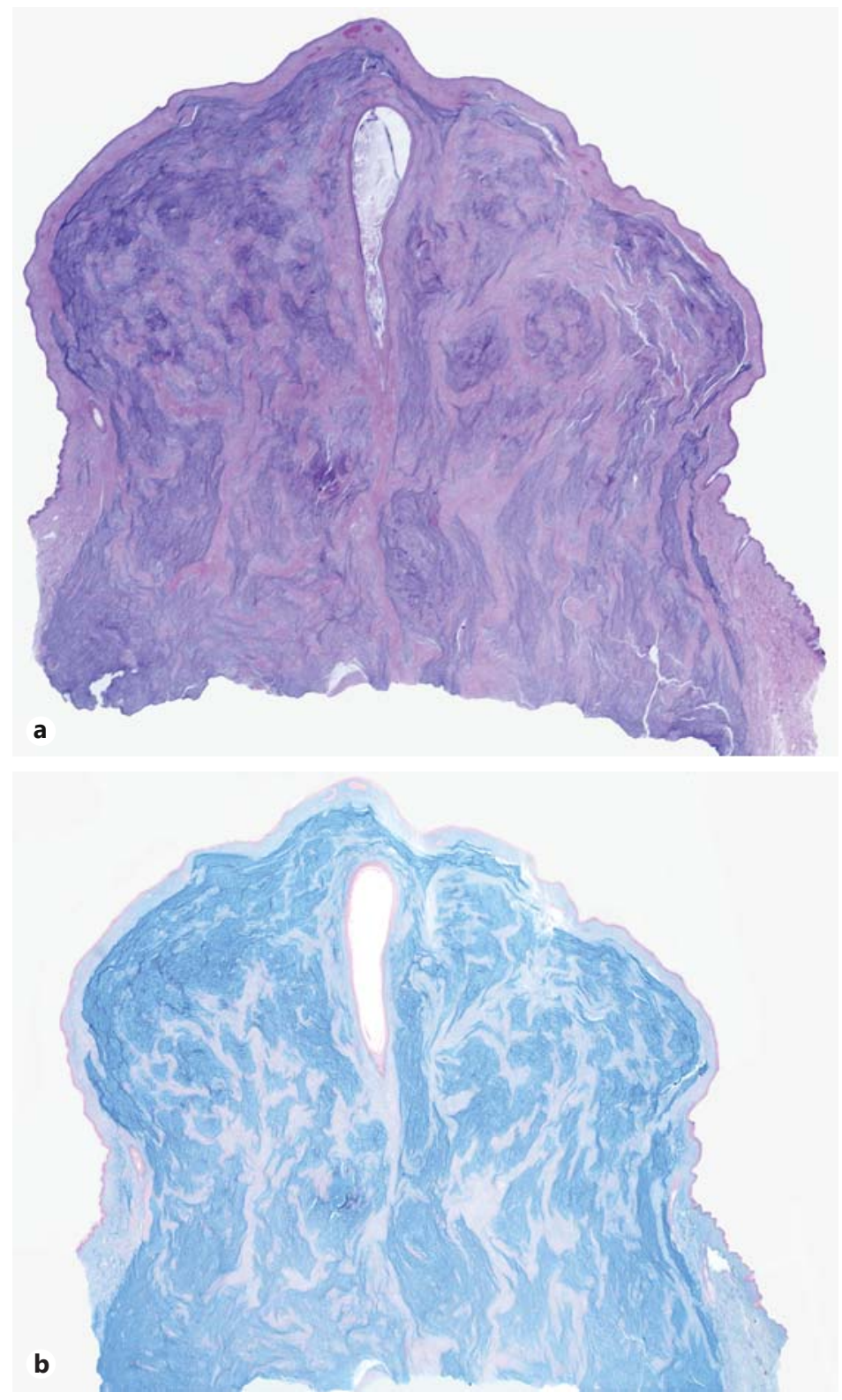

indolent behavior. An association with Carney complex has not been reported for any of the cases. Microscopically, NMB consists of a myxoid proliferation containing scattered benignlooking spindle cells, usually with myofibroblastic characteristics, and some vessels. The histopathological hallmark of this lesion is its multinodular configuration, maintaining preexisting breast ducts in the collagenous tracts that separate the nodules.

\section{Case Report}

A 46-year-old man without any relevant personal or familial history presented a progressive enlargement of his left nipple over the course of 1 year. The lesion was totally asymptomatic, and no secretion was ever noticed by the patient. On physical examination, 
Fig. 2. Multifocal areas of myxoid proliferation with ill-defined boundaries intermixed with sclerotic tissue.

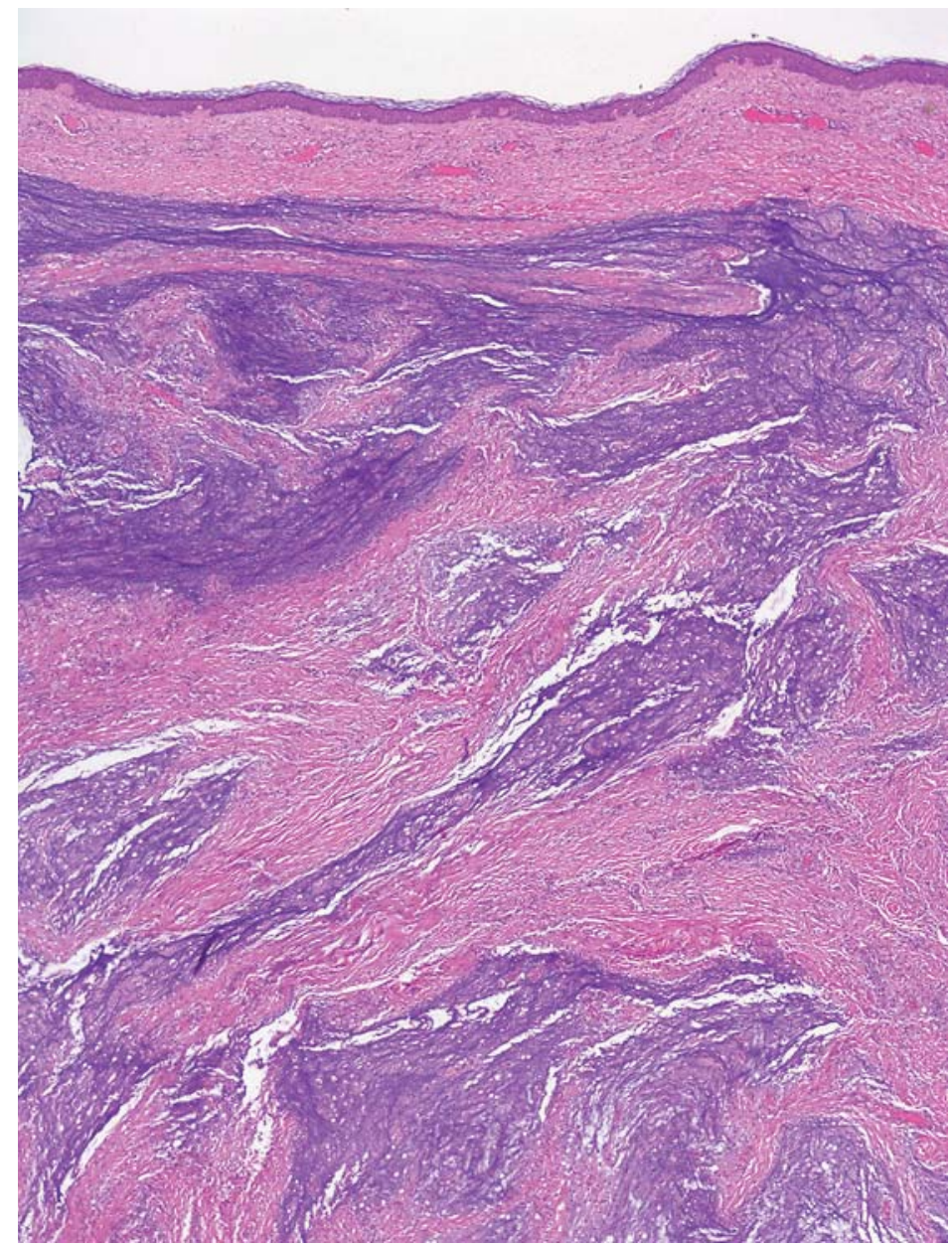

there was a diffuse enlargement of the nipple that was elastic and nontender under pressure. The clinical diagnosis was epidermal cyst, lipoma or neurofibroma.

Histopathologically, the specimen contained a myxoid lesion centered in the nipple area, which was noticeably enlarged (fig. 1). The proliferation presented a conspicuous multilobular pattern (fig. 1,2) with thick fibrocollagenous bands interspersed among the myxoid lobules. Occasional breast ducts were observed in the fibrocollagenous septa (fig. 3), but they were completely absent from the myxoid nodules. The vascularization was not prominent, but some dilated blood vessels of variable size were observed inside the lobules and within the interstitial collagenous bands. In mostareas, thelesion consisted of large pools of mucinous material with sparse spindle cells, some of them with long slender cytoplasms. There were also microscopic foci with higher cellular density, usually having a myofibroblastic appearance (fig. 4). In addition, some stellate cells surrounded by clear halos of a chondroid appearance were observed focally (fig. 3, 5). The peripheral outline was irregular at the base of the lesion, with foci of the myxoid tissue merging imperceptibly with the breast fat tissue, whereas in other areas, the lesion was quite well circumscribed (fig. 5). Alcian blue at a pH of 2.5 and colloidal iron stains highlighted the myxoid stroma (fig. 1b). Immunohistochemical studies demonstrated a diffuse and intense expression of CD34 (fig. 6a); $\alpha$-smooth muscle actin (fig. 6b), calponin and S100 (fig. 6c) were also expressed diffusely, albeit with faint-tomoderate intensity, whereas desmin was negative. Wide-spectrum keratins, epithelial membrane antigen and factor XIIIa were negative, although numerous factor XIIIa-positive 


\section{Dermato pathology}

Fig. 3. Fibrocollagenous septa containing preexisting ducts between two foci of myxoid proliferation with stellate cells surrounded by clear halos.

Fig. 4. Loosely arranged fascicle of spindle cells with slender cytoplasms in a myxoid background.

Fig. 5. At the base, the lesion boundaries tended to be well demarcated.

\begin{tabular}{l|l}
\hline Dermatopathology 2014;1:47-54 \\
\hline DOI: 10.1159/000364859 & $\begin{array}{l}\text { @ } 2014 \text { S. Karger AG, Basel } \\
\text { www.karger.com/dpa }\end{array}$ \\
\hline
\end{tabular}

Fernández-Figueras et al.: Nodular Mucinosis in a Male Breast
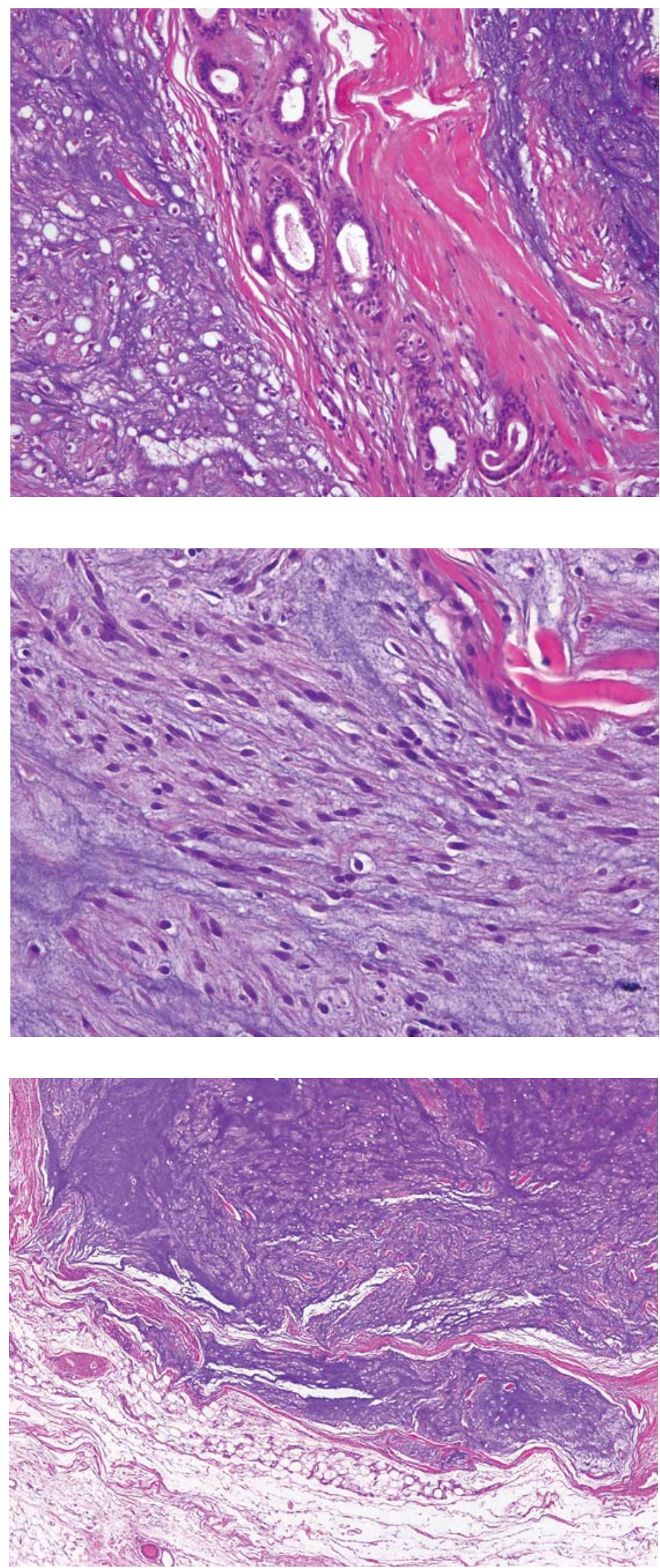


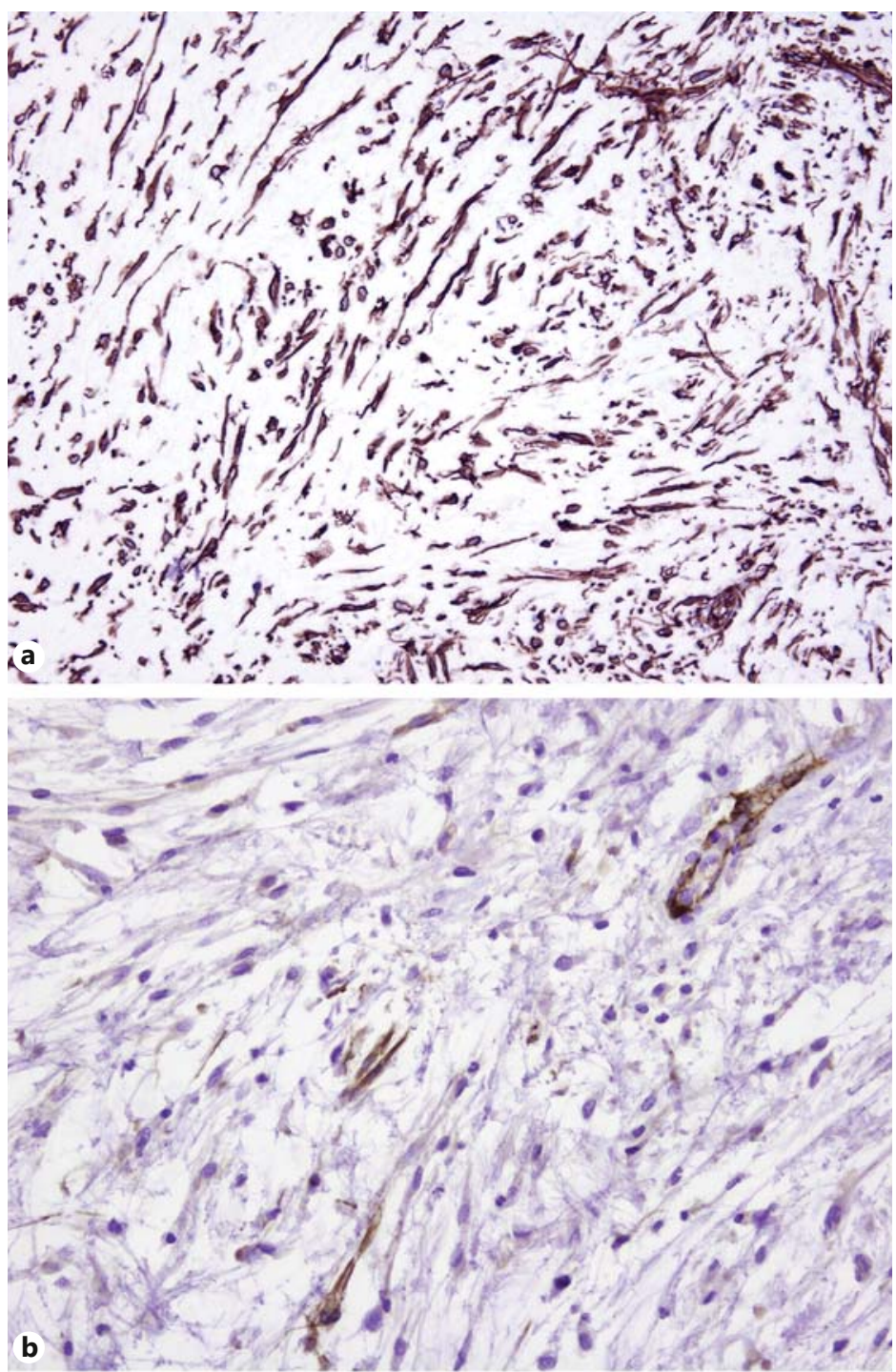

Fig. 6. The immunoprofile was characterized by a diffuse expression of CD34 (a), weak-to-moderate expression of actin (b) and weak but noticeable expression of S100 protein (c).

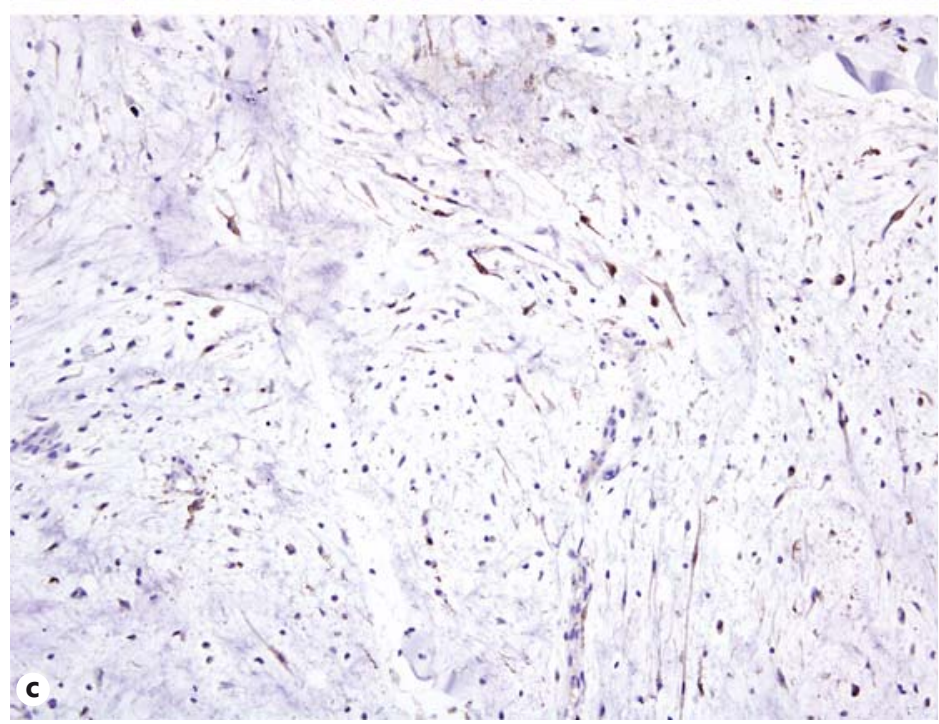


Table 1. Review of the cases considered NMB currently reported in the English literature

\begin{tabular}{|c|c|c|c|c|c|}
\hline $\begin{array}{l}\text { Gender/ } \\
\text { age }\end{array}$ & $\begin{array}{l}\text { First author, } \\
\text { year of publication }\end{array}$ & $\begin{array}{l}\text { Associated } \\
\text { pathology }\end{array}$ & Location & Size & Follow-up \\
\hline $\mathrm{F} / 20$ & Wee [2], 1989 & & right areola & $6 \mathrm{~cm}$ & - \\
\hline$F / 37$ & $\begin{array}{l}\text { Vázquez-Doval [3], } \\
1996\end{array}$ & $\begin{array}{l}\text { mycosis } \\
\text { fungoides }\end{array}$ & right areola & & $\begin{array}{l}\text { lesion almost } \\
\text { disappeared after } \\
\text { photochemotherapy }\end{array}$ \\
\hline $\mathrm{M} / 40$ & Michal [1], 1998 & - & left nipple & $2 \times 1.5 \times 1.5 \mathrm{~cm}$ & 6 years \\
\hline $\mathrm{F} / 28$ & Michal [1], 1998 & - & right nipple & $1.5 \times 1.5 \times 1 \mathrm{~cm}$ & 3 years \\
\hline $\mathrm{F} / 29$ & Michal [1], 1998 & - & right nipple & $2.5 \times 2.5 \times 2 \mathrm{~cm}$ & 6 months \\
\hline $\mathrm{F} / 30$ & Koide [4], 2002 & - & $\begin{array}{l}\text { upper outer } \\
\text { quadrant close } \\
\text { to the right } \\
\text { nipple }\end{array}$ & $2.9 \times 2.1 \mathrm{~cm}$ & 6 months \\
\hline $\mathrm{F} / 21$ & Sanati [5], 2005 & - & left nipple & $1.5 \times 0.9 \times 0.8 \mathrm{~cm}$ & - \\
\hline $\mathrm{F} / 15$ & Manglick [6], 2010 & - & $\begin{array}{l}\text { supernumerary } \\
\text { nipple }\end{array}$ & $3 \times 1.2 \times 1.2 \mathrm{~cm}$ & - \\
\hline $\mathrm{F} / 16$ & Rosen [7], 2009 & - & nipple & - & - \\
\hline Unknown & Rosen [7], 2009 & - & - & & - \\
\hline$F / 74$ & Chisholm [8], 2009 & $\begin{array}{l}\text { breast } \\
\text { carcinoma }\end{array}$ & $\begin{array}{l}\text { right subareolar } \\
\text { lesion }\end{array}$ & $0.9 \times 0.8 \times 0.3 \mathrm{~cm}$ & - \\
\hline $\mathrm{M} / 46$ & present report & - & left nipple & $3.2 \times 2.4 \times 2 \mathrm{~cm}$ & 3 years \\
\hline
\end{tabular}

Cases that might represent trauma-induced cutaneous focal mucinosis of the mammary areola are set in italics.

dendritic cells were present throughout the tumor. Estrogen and progesterone receptors were not expressed within the proliferating spindle cells. The proliferation marker Ki-67 stained $1.4 \%$ of the tumor nuclei. The lesion was focally in contact with the surgical margins, but the patient is free of relapse after 3 years.

\section{Discussion}

NMB is a term coined by Michal et al. [1] in 1998 to denominate a myxoid lesion located in the nipple and areola that usually occurs in young women. Nevertheless, the first reported case is considered to be a 6-cm lesion in a 20-year-old woman, originally interpreted as a nerve sheath myxoma of the breast by Wee et al. [2] in 1989. Since then, only a small number of cases [3-8] of this rare lesion have been reported, none of them in association with Carney complex. Our case is the second one occurring in a man. The main characteristics of all the cases are summarized in table 1.

Most of the cases reported [1, 2, 4-7] share microscopic features that, in our opinion, are very suggestive of a distinctive entity. Clinically, they correspond to asymptomatic masses that measure from 1.5 to $6 \mathrm{~cm}$ in diameter and are located in the dermis and subcutaneous tissue of the nipple, areola or supernumerary nipple of young-to-middle-aged patients. In 
these cases, an association with local inflammation or trauma has never been reported. Microscopically, their common denominator is the presence of a multilobular myxoid proliferation that is moderately well circumscribed but not encapsulated. A sparse, randomly distributed spindle cell population and some dilated vessels are present within the mucinous background, which is intermingled with preexisting breast ducts. Nevertheless, ducts are only present at the edge of the myxoid nodules or inside the fibrocollagenous bands that delimitate them, but never in their central areas.

Conversely, other cases considered in the literature to be NMB do not fit this profile. A patient with mycosis fungoides from the areola has been included in two reviews of previous cases $[5,6]$. Instead of a nodule, that patient presented a diffuse dermal cutaneous mucinosis in the area underlying the lymphoid proliferation. In addition, the lesion disappeared almost completely with psoralen photochemotherapy for mycosis fungoides. In view of these findings, we believe that lesion was a secondary phenomenon either related to the cutaneous lymphoma or included in the spectrum of trauma-induced cutaneous focal mucinosis of the areola [9]. Another recently reported case [8] was a 1-cm mucinous nodule in the areola of an elderly woman. She had a past history of a mucinous (colloid) carcinoma in the same breast, treated with partial mastectomy and local radiotherapy. The lesion lacked the multinodular architecture typical of NMB cases, and the mucinous material splaying the collagenous fibers apart contained scattered histiocytes and capillary vessels but was devoid of spindle cells. Again, we believe that both the history and the microscopic appearance would rather correspond to trauma-induced cutaneous focal mucinosis of the areola [9].

Although our case fulfills the clinical and microscopic criteria proposed for the diagnosis of NMB, its positive immunoreactivity for CD34 and S100 protein is at odds with the immunoprofile of previously described instances of NMB. This interesting finding led us to consider $\mathrm{NMB}$ as a soft tissue tumor in the spectrum of myofibroblastoma and spindle cell lipoma. Our hypothesis is based on the myofibroblastic nature of the spindle cell population in NMB, as shown by the observation of actin and calponin expression in several NMB cases [5-7]. In concordance with this, Rosen [7] claimed that NMB belongs to the spectrum of myofibroblastoma of the breast and described that, as happens in the present case, myofibroblastoma may express CD34 [7]. Hence, the immunohistochemical coexpression of CD34, actin and calponin in our case would favor the existence of a link between NMB and myofibroblastoma. On the other hand, it is widely accepted that myofibroblastoma and spindle cell lipoma share many features [10], including genetic aberrations [11], and it is well known that their morphologic findings may occasionally overlap [12]. Thus, it seems reasonable to assume that NMB may also be related to spindle cell lipoma, which typically expresses CD34 and may rarely be positive for S100 protein [12], like the case herein reported.

As previously discussed, the main differential diagnosis of NMB is trauma-induced cutaneous focal mucinosis of the areola [9]. Myxoid fibroadenomas and mammary myxomas (usually associated with Carney complex) should also be included in this differential diagnosis, although they tend to be more deeply located in the breast parenchyma. Breast mucocele-like lesions and mucinous carcinomas typically contain benign or malignant epithelial cells, and it is mandatory to rule out this possibility by a careful study of many sections and by immunohistochemical staining for wide-spectrum keratins. Neurofibromas may also be included in this differential diagnosis, since some cases are predominantly myxoid and their immunoprofile includes the expression of CD34 and S100 protein. However, the presence of neurofilaments rules out a diagnosis of NMB. Also to be distinguished from NMB is neurothekeoma, which may contain CD34-positive cells and is characterized by a myxoid multilobular configuration, even though it is devoid of fibrocollagenous bands and its mesenchymal cells do not resemble myofibroblasts. 
In summary, we consider that a multilobular growth pattern with (1) the presence of breast ducts only in fibrocollagenous interstitial bands and (2) the absence of a previous local pathology able to justify a mucin-reactive deposition is the essential criterion for the diagnosis of NMB. In addition, we believe that NMB should be considered a superficial myxoid myofibroblastoma of the breast, probably in the spectrum with spindle cell lipoma. In addition to the fact that these lesions exhibit similar immunohistochemical profiles, it is also to be expected that future molecular studies will demonstrate commonalities in their genetic aberrations.

\section{References}

1 Michal M, Ludvíková M, Zámecník M: Nodular mucinosis of the breast: report of three cases. Pathol Int 1998; 48:542-544.

-2 Wee A, Tan CE, Raju GC: Nerve sheath myxoma of the breast. A light and electron microscopic, histochemical and immunohistochemical study. Virchows Arch A Pathol Anat Histopathol 1989;416:163-167.

-3 Vázquez-Doval FJ, Sola MA: Mucinosis of the mammary areolae and mycosis fungoides. Clin Exp Dermatol 1996;21:374-376.

4 Koide N, Akashi-Tanaka S, Fukutomi T, Nanasawa T, Hasegawa T: Nodular mucinosis of the breast: a case report with clinical and imaging findings. Breast Cancer 2002;9:261-264.

5 Sanati S, Leonard M, Khamapirad T, Eltorky MA: Nodular mucinosis of the breast: a case report with pathologic, ultrasonographic, and clinical findings and review of the literature. Arch Pathol Lab Med 2005;129:e58e61.

6 Manglik N, Berlingeri-Ramos AC, Boroumand N, Eltorky M: Nodular mucinosis of the breast in a supernumerary nipple: case report and review of the literature. J Cutan Pathol 2010;37:1178-1181.

7 Rosen PP: Rosen's Breast Pathology, ed 3. Philadelphia, Lippincott Williams \& Wilkins, 2009.

8 Chisholm C, Greene JF Jr: Nodular mucinosis of the breast: expanding our understanding with an unusual case. Am J Dermatopathol 2010;32:187-189.

-9 Kempf W, von Stumberg B, Denisjuk N, Bode B, Rongioletti F: Trauma-induced cutaneous focal mucinosis of the mammary areola: an unusual presentation. Dermatopathology 2014;1:24-28.

10 McMenamin ME, Fletcher CD: Mammary-type myofibroblastoma of soft tissue: a tumor closely related to spindle cell lipoma. Am J Surg Pathol 2001;25:1022-1029.

11 Pauwels P, Sciot R, Croiset F, Rutten H, van den Berghe H, Dal Cin P: Myofibroblastoma of the breast: genetic link with spindle cell lipoma. J Pathol 2000;191:282-285.

12 Ibrahim HA, Shousha S: Myofibroblastoma of the female breast with admixed but distinct foci of spindle cell lipoma: a case report. Case Rep Pathol 2013;2013:738014. 